\title{
Usefulness of Genetic Testing in Sudden Cardiac Arrest Survivors With or Without Previous Clinical Evidence of Heart Disease
}

Asatryan, Babken ; Schaller, André ; Seiler, Jens ; Servatius, Helge ; Noti, Fabian ; Baldinger, Samuel H ; Tanner, Hildegard ; Roten, Laurent ; Dillier, Roger ; Lam, Anna ; Haeberlin, Andreas ; Conte, Giulio ; Saguner, Ardan M ; Müller, Stephan Andreas ; Duru, Firat ; Auricchio, Angelo ; Ammann, Peter ; Sticherling, Christian ; Burri, Haran ; Reichlin, Tobias ; Wilhelm, Matthias ; Medeiros-Domingo, Argelia

\begin{abstract}
Genetic testing in survivors of sudden cardiac arrest (SCA) with a suspicious cardiac phenotype is considered clinically useful, whereas its value in the absence of phenotype is disputed. We aimed to evaluate the clinical utility of genetic testing in survivors of SCA with or without cardiac phenotype. Sixty unrelated SCA survivors (median age: 34 [interquartile range 20 to 43 ] years, $82 \%$ male) without coronary artery disease were included: $24(40 \%)$ with detectable cardiac phenotype $(\mathrm{Ph}(+) \mathrm{SCA})$ after the SCA event and $36(60 \%)$ with no clear cardiac phenotype (Ph(-)SCA). The targeted exome sequencing was performed using the TruSight-One Sequencing Panel (Illumina). Variants in 185 clinically relevant cardiac genes with minor allele frequency $<1 \%$ were analyzed. A total of 32 pathogenic or likely pathogenic variants were found in 27 (45\%) patients: $17(71 \%)$ in the $\mathrm{Ph}(+) \mathrm{SCA}$ group and $10(28 \%)$ in the $\mathrm{Ph}(-) \mathrm{SCA}$ group. Sixteen $(67 \%) \mathrm{Ph}(+) \mathrm{SCA}$ patients hosted mutations congruent with the suspected phenotype, in which $12(50 \%)$ were cardiomyopathies and 4 (17\%) channelopathies. In $\mathrm{Ph}(-) \mathrm{SCA}$ cases, 6 (17\%) carried a mutation in cardiac ion channel genes that could explain the event. The additional 4 (11\%) mutations in this group, could not explain the phenotype and require additional studies. In conclusion, cardiac genetic testing was positive in nearly $2 / 3$ patients of the $\mathrm{Ph}(+) \mathrm{SCA}$ group and in $1 / 6$ of the $\mathrm{Ph}(-) \mathrm{SCA}$ group. The test was useful in both groups to identify or confirm an inherited heart disease, with an important impact on the patient care and first-degree relatives at risk.
\end{abstract}

DOI: https://doi.org/10.1016/j.amjcard.2019.02.061

Posted at the Zurich Open Repository and Archive, University of Zurich

ZORA URL: https://doi.org/10.5167/uzh-173218

Journal Article

Accepted Version

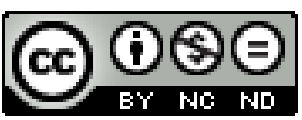

The following work is licensed under a Creative Commons: Attribution-NonCommercial-NoDerivatives 4.0 International (CC BY-NC-ND 4.0) License.

Originally published at:

Asatryan, Babken; Schaller, André; Seiler, Jens; Servatius, Helge; Noti, Fabian; Baldinger, Samuel H; Tanner, Hildegard; Roten, Laurent; Dillier, Roger; Lam, Anna; Haeberlin, Andreas; Conte, Giulio; Saguner, Ardan M; Müller, Stephan Andreas; Duru, Firat; Auricchio, Angelo; Ammann, Peter; Sticherling, 
Christian; Burri, Haran; Reichlin, Tobias; Wilhelm, Matthias; Medeiros-Domingo, Argelia (2019). Usefulness of Genetic Testing in Sudden Cardiac Arrest Survivors With or Without Previous Clinical Evidence of Heart Disease. American Journal of Cardiology, 123(12):2031-2038.

DOI: https://doi.org/10.1016/j.amjcard.2019.02.061 


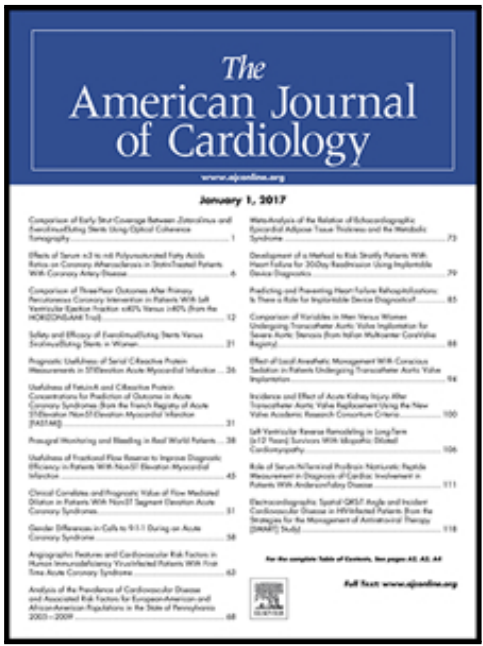

Usefulness of Genetic Testing in Sudden Cardiac Arrest Survivors With or Without Previous Clinical Evidence of Heart Disease

Babken Asatryan MD , André Schaller PhD , Jens Seiler MD , Helge Servatius MD, Fabian Noti MD, Samuel H. Baldinger MD, Hildegard Tanner MD , Laurent Roten MD , Roger Dillier MD , Anna Lam MD , Andreas Haeberlin MD, PhD , Giulio Conte MD, PhD , Ardan M. Saguner MD , Stephan Andreas Müller MD , Firat Duru MD , Angelo Auricchio MD, PhD, Peter Ammann MD , Christian Sticherling MD , Haran Burri MD , Tobias Reichlin MD , Matthias Wilhelm MD , Argelia Medeiros-Domingo MD, PhD

PII:

DOI:

Reference: S0002-9149(19)30329-7 https://doi.org/10.1016/j.amjcard.2019.02.061 AJC 23864

To appear in: The American Journal of Cardiology

Received date: 17 December 2018

Revised date: 17 February 2019

Please cite this article as: Babken Asatryan MD, André Schaller PhD, Jens Seiler MD, Helge Servatius MD , Fabian Noti MD , Samuel H. Baldinger MD , Hildegard Tanner MD , Laurent Roten MD , Roger Dillier MD , Anna Lam MD , Andreas Haeberlin MD, PhD , Giulio Conte MD, PhD , Ardan M. Saguner MD , Stephan Andreas Müller MD , Firat Duru MD , Angelo Auricchio MD, PhD , Peter Ammann MD , Christian Sticherling MD , Haran Burri MD , Tobias Reichlin MD, Matthias Wilhelm MD , Argelia Medeiros-Domingo MD, PhD , Usefulness of Genetic Testing in Sudden Cardiac Arrest Survivors With or Without Previous Clinical Evidence of Heart Disease, The American Journal of Cardiology (2019), doi: https://doi.org/10.1016/j.amjcard.2019.02.061

This is a PDF file of an unedited manuscript that has been accepted for publication. As a service to our customers we are providing this early version of the manuscript. The manuscript will undergo copyediting, typesetting, and review of the resulting proof before it is published in its final form. Please note that during the production process errors may be discovered which could affect the content, and all legal disclaimers that apply to the journal pertain. 


\section{Usefulness of Genetic Testing in Sudden Cardiac Arrest Survivors With or Without Previous Clinical Evidence of Heart Disease}

Short title: Genetic Basis of Sudden Cardiac Arrest

Babken Asatryan, $\mathrm{MD}^{\mathrm{a}}$, André Schaller, $\mathrm{PhD}^{\mathrm{b}}$, Jens Seiler, $\mathrm{MD}^{\mathrm{a}}$, Helge Servatius, $\mathrm{MD}^{\mathrm{a}}$, Fabian Noti, MD ${ }^{\mathrm{a}}$, Samuel H. Baldinger, MD ${ }^{\mathrm{a}}$, Hildegard Tanner, MD ${ }^{\mathrm{a}}$, Laurent Roten, MD ${ }^{\mathrm{a}}$, Roger Dillier, $\mathrm{MD}^{\mathrm{c}}$, Anna Lam, MD ${ }^{\mathrm{a}, \mathrm{d}}$, Andreas Haeberlin, MD, $\mathrm{PhD}^{\mathrm{a}}$, Giulio Conte, MD, $\mathrm{PhD}^{\mathrm{e}}$, Ardan M. Saguner, $\mathrm{MD}^{\mathrm{f}}$, Stephan Andreas Müller, $\mathrm{MD}^{\mathrm{c}}$, Firat Duru, $\mathrm{MD}^{\mathrm{f}}$, Angelo Auricchio, MD, $\mathrm{PhD}^{\mathrm{e}}$, Peter Ammann, $\mathrm{MD}^{\mathrm{g}}$, Christian Sticherling, $\mathrm{MD}^{\mathrm{h}}$, Haran Burri, MD, Tobias Reichlin, $\mathrm{MD}^{\mathrm{a}}$, Matthias Wilhelm, MD ${ }^{\mathrm{a}}$, Argelia Medeiros-Domingo, $\mathrm{MD}, \mathrm{PhD}^{\mathrm{a}}{ }^{*}$

a Department of Cardiology, Inselspital, Bern University Hospital, University of Bern, Switzerland

${ }^{\mathrm{b}}$ Division of Human Genetics, Department of Pediatrics, Inselspital, Bern University Hospital, University of Bern, Switzerland

${ }^{\mathrm{c}}$ Stadtspital Triemli, Zurich, Switzerland

${ }^{\mathrm{d}}$ Hôpital Cardiologique du Haut-Lévêque - CHU de Bordeaux, Bordeaux-Pessac, France

${ }^{\mathrm{e}}$ Division of Cardiology, Fondazione Cardiocentro Ticino, Lugano, Switzerland

${ }^{\mathrm{f}}$ University Heart Center Zurich, Zurich, Switzerland

${ }^{g}$ Kantonsspital, St. Gallen, Switzerland

${ }^{\text {h }}$ Department of Cardiology, University Hospital Basel, Basel, Switzerland

${ }^{\mathrm{i}}$ University Hospital of Geneva, Geneva, Switzerland

\section{*Corresponding author:}

Argelia Medeiros-Domingo

Department of Cardiology, Inselspital, 3010 Bern, Switzerland.

Phone: +41316320363 Fax: +41316321414

E-mail: argelia.medeiros@hin.ch

\section{Declaration of interest}

Dr. Saguner reports personal fees from Boston Scientific, and grants from Biosense Webster, Biotronik, Abbott, and BMS Pfizer, outside the submitted work. Dr. Müller reports personal fees from Biotronik, Medtronic, St. Jude Medical/ Abbott, Biosense Webster, AstraZeneca, Daiichi Sankyo, LivaNova/ Sorin, and MSD, and training support from Biotronik, Boston Scientific, Medtronic, and Biosence Webster, outside the submitted work. Prof. Auricchio serves as a consultant to Abbott, Biosense Webster, Daiichi-Sankyo, Boston Scientific, CardiotekSchwarzer, Cordis Biologics Delivery Systems, and Medtronic. He also received speaker fees from Abbott, Biosense-Webster, Daiichi-Sankyo, Boston Scientific, and Medtronic. Other authors have no conflicts of interests to declare. 


\section{Abstract}

Genetic testing in survivors of sudden cardiac arrest (SCA) with a suspicious cardiac phenotype is considered clinically useful, whereas its value in the absence of phenotype is disputed. We aimed to evaluate the clinical utility of genetic testing in survivors of SCA with or without cardiac phenotype. Sixty unrelated SCA survivors (median age: 34 [IQR 20-43] years, 82\% male) without coronary artery disease were included: 24 (40\%) with detectable cardiac phenotype $(\mathrm{Ph}(+) \mathrm{SCA})$ after the SCA event and $36(60 \%)$ with no clear cardiac phenotype $(\mathrm{Ph}(-) \mathrm{SCA})$. Either targeted exome sequencing was performed using the TruSight-One Sequencing Panel (Illumina). Variants in 185 clinically relevant cardiac genes with minor allele frequency $<1 \%$ were analyzed. A total of 32 pathogenic or likely pathogenic variants were found in 27 (45\%) patients: $17(71 \%)$ in the $\mathrm{Ph}(+) \mathrm{SCA}$ group and $10(28 \%)$ in the $\mathrm{Ph}(-) \mathrm{SCA}$ group. Sixteen $(67 \%)$ $\mathrm{Ph}(+)$ SCA patients hosted mutations congruent with the suspected phenotype, in which $12(50 \%)$ were cardiomyopathies and $4(17 \%)$ channelopathies. Among $\mathrm{Ph}(-) \mathrm{SCA}$ cases, $6(17 \%)$ carried a mutation in cardiac ion channel genes that could explain the event. The additional $4(11 \%)$ mutations in this group, could not explain the phenotype and require additional studies. In conclusion, cardiac genetic testing was positive in nearly $2 / 3$ patients of the $\mathrm{Ph}(+) \mathrm{SCA}$ group and in $1 / 6$ of the $\mathrm{Ph}(-) \mathrm{SCA}$ group. The test was useful in both groups to identify or confirm an inherited heart disease, with an important impact on the patient care and first-degree relatives at risk.

Keywords: idiopathic ventricular fibrillation; cardiac channelopathy; cardiomyopathy; genetic testing; sudden cardiac death 


\section{INTRODUCTION}

Sudden cardiac arrest (SCA) is a common manifestation of a wide spectrum of inherited and acquired cardiovascular diseases, and extra-cardiac pathologies. ${ }^{1}$ Identifying the cause of SCA is essential for proper management of the arrhythmic substrate to allow a personalized approach. The detection of a specific cardiomyopathy or inherited arrhythmia phenotype in a SCA survivor $(\mathrm{Ph}(+) \mathrm{SCA})$ allows genetic testing for confirmation of the clinical diagnosis, risk stratification, and eventually specific therapy. ${ }^{2,3}$ Phenotype-guided genetic testing has shown a heterogeneous diagnostic yield of $9-60 \%$ in SCA survivors, depending on the panel and technology used. $^{4-6}$ In the absence of a clear cardiac phenotype, the event is referred to as a phenotype-negative SCA (Ph(-)SCA), or idiopathic ventricular fibrillation. ${ }^{7}$ Genetic testing in $\mathrm{Ph}(-)$ SCA has been discouraged by the expert consensus (class III) to avoid possible overdiagnosis and unnecessary interventions in families owing to potential misinterpretation of innocent bystander variants,. ${ }^{2,7}$ Thus, currently the knowledge on genetic basis of $\mathrm{Ph}(-) \mathrm{SCA}$ is limited. In this study, we sought to evaluate the clinical and genetic characteristics of an unselected cohort of SCA survivors referred for genetic testing from different regions of Switzerland.

\section{METHODS}

In this partly prospective and partly retrospective study we included SCA patients referred to the Bern University Hospital for genetic testing between January 2014 and May 2018. SCA was defined as an unexpected circulatory arrest with cardiovascular collapse and documented hemodynamically unstable sustained ventricular tachycardia (VT) or ventricular fibrillation (VF), restored by cardioversion or defibrillation, as appropriate. Internationally accepted criteria were used to diagnose/exclude specific diseases. Initial diagnostic workup included personal and family history, 12-lead resting ECG, echocardiography and coronary angiogram/ cardiac 
computed tomography, exercise stress test (whenever possible); additional examination with cardiac MRI, electrophysiological study, or provocative testing were performed when considered clinically indicated. Patients with coronary artery disease, myocarditis, sarcoidosis, systemic diseases affecting the heart, secondary cardiomyopathies, or reversible causes of SCA were excluded from the study. Survivors of SCA with any suspicious or robust cardiac phenotype $(\mathrm{Ph}(+) \mathrm{SCA})$ and those with no identified phenotype $(\mathrm{Ph}(-) \mathrm{SCA})$ were included in this study. This study was conducted in full agreement with the principles outlined in the Declaration of Helsinki. The study protocol was approved by the Ethical Commission of the Canton Bern.

Genomic DNA was extracted from EDTA-blood using standard procedures. Clinical exome analysis was performed using next-generation sequencing on MiSeq or NextSeq 500 instrument using either the TruSight One or TruSight One expanded Sequencing Panel (Illumina, San Diego, CA), which provide comprehensive coverage of exons and flanking intronic sequences of 4813 and 6794 clinically relevant genes, respectively. The intronic coverage comprised at least 30 to $50 \mathrm{bp}$ of each intron; the coverage depth of exons was minimum 30x. After sequencing, variants in 185 genes associated with hereditary cardiovascular diseases were analyzed (Supplementary Table 1). Read alignment and local realignment of indels were performed using CLC Genomic Workbench v7.5.1 or CLC Biomedical Genomic Workbench v5.0 (Qiagen, Redwood City, CA). Novel or putative disease-associated variants were analyzed using the following filtering criteria: protein's primary structure, species conservation of the affected amino acid and an allele frequency $<1 \%$ based on the 1000 Genome Project database. Exonic variants below 1\% frequency in the Exome Aggregation Consortium browser, including +/- 8bp flanking intronic variants, were further analyzed. For titin (TTN), only radical mutations (i.e. nonsense, frameshift, and splice-site mutations) were considered as putative pathogenic variants. The final interpretation of variants was performed according to the guidelines 
established by the American College of Medical Genetics and Genomics (ACMG). ${ }^{8}$

Categorical variables are presented as numbers and percentages; quantitative variables are presented as median (interquartile range $[\mathrm{IQR}]$ ) for non-normally distributed variables. Categorical variables were compared using Chi-Square or Fisher's exact test, as appropriate. Continuous variables were compared using Student's t test or Mann-Whitney $U$ test, as appropriate. To adjust for multiple testing, we used Bonferroni adjustment and set alpha at 0.005. Statistical analyses were performed using IBM SPSS Statistics for Windows, Versíon 25.0. IBM Corp. All tests were 2-tailed, with a $\mathrm{p}<0.05$ considered significant.

\section{RESULTS}

Sixty unrelated SCA patients (median age 34 [20-43] years; male-82\%) without previously known heart disease, including $24(40 \%)$ with $(\mathrm{Ph}(+) \mathrm{SCA})$ and $36(60 \%)$ with $\mathrm{Ph}(-) \mathrm{SCA}$, were enrolled (Table 1). The two groups were similar in terms of age at SCA and gender distribution. Data regarding the circumstances of SCA were available in $28(47 \%)$ patients. In $13(22 \%)$ cases the event occurred at the time or shortly after exercise activities and in $15(25 \%)$ occurred unrelated to sports activities. The proportion of exercise-related SCA cases were similar in both groups (19\% vs $25 \%, \mathrm{p}=0.609)$. Twelve $(92 \%)$ out of 13 exercise-related SCA cases occurred in males, but males were not more likely to experience a SCA during exercise, than the females $(\mathrm{p}=0.263)$.

Overall, 32 putative pathogenic variants (14 novel and 18 previously reported) were identified in 27 (45\%) out of 60 subjects (Table 2). No variants have been identified more than once in our cohort. Patients with exercise-related SCA had a likelihood of having a positive result of genetic testing (54\%) similar to those with exercise-unrelated (40\%) or unknown circumstances of SCA (44\%; $\mathrm{p}=0.747)$.

In the $\mathrm{Ph}(+) \mathrm{SCA}$ group, dilated cardiomyopathy (DCM, $\mathrm{n}=7$ ) was the most common, 
followed by hypertrophic cardiomyopathy $(n=4)$ and arrhythmogenic right-ventricular cardiomyopathy (ARVC, n=4). Other phenotypes included left-ventricular non-compaction, catecholaminergic polymorphic ventricular tachycardia $(\mathrm{CPVT}, \mathrm{n}=2)$, mitral valve prolapse $(\mathrm{n}=2)$, long QT syndrome $(\mathrm{n}=1)$, short QT syndrome $(\mathrm{n}=1)$, and progressive cardiac conduction disease $(n=1)$. Twenty-one putative pathogenic variants were identified in $17(71 \%)$ out of 24 $\mathrm{Ph}(+)$ SCA patients, including $14(67 \%)$ mutations in cardiomyopathy-associated genes (LMNA, TNNT2, TNNI3, TTN, FLNC, PKP2, DSP, JPH2, TNXB, LAMP2, BAG3, and CAV3) and 7 (33\%) in cardiac ion channel genes (RYR2, CASQ2, SCN5A, KCNQ1, and HCN4). In 13 out of 17 (76\%) genotype-positive patients a cardiomyopathy and in 4 (24\%) cardiac channelopathy was suspected (Figure 1). Sixteen (67\%) out of $24 \mathrm{Ph}(+) \mathrm{SCA}$ patients carried mutations in agreement with the observed phenotype, whereas 1 patient, a 31-year-old male, carried a likely pathogenic variant in the $C A V 3$ (caveolin 3) gene, which/so far has not been associated with the identified DCM phenotype; thus it was considered suspicious but not diagnostic.

Overall, 11 pathogenic or likely pathogenic variants were detected in $10(28 \%)$ out of 36 $\mathrm{Ph}(-)$ SCA survivors (Figure 1), which was significantly lower than the $71 \%$ diagnostic yield in $\mathrm{Ph}(+)$ SCA patients $(\mathrm{p}=0.017)$. Six $(17 \%)$ subjects carried mutations in ion channel genes (SCN5A, RYR2, and KCNE2), that could explain the SCA in the absence of phenotype (concealed channelopathies). Additionally, 5 putative pathogenic variants localized in the RANGRF, ABCC9, TRPM4, DSP and TTN did not clarify the SCA event and require further functional studies or segregation analysis.

\section{DISCUSSION}

In a cohort of 60 SCA survivors without previously known heart disease, the cardiac panel genetic testing detected 32 putative pathogenic variants in $27(45 \%)$ cases. In patients with an identifiable cardiac phenotype, the genetic test could explain the phenotype and the SCA in 16 
(67\%) cases, while in those with no phenotype, the genetic test could clarify the cause of the SCA in $6(17 \%)$ cases. Approximately $20 \%$ of all patients with SCA were found to have an association with sports activities or physical work.

Our $\mathrm{Ph}(+)$ SCA cohort included cases with a wide variety of cardiac phenotypes, which once again highlights the broad spectrum of heritable heart diseases underlying SCA. As expected, the diagnostic yield was 2-fold higher in the $\mathrm{Ph}(+) \mathrm{SCA}$ group than in the $\mathrm{Ph}(-) \mathrm{SCA}$. Interestingly, the diagnostic yield of $71 \%$ in the $\mathrm{Ph}(+) \mathrm{SCA}$ group surpassed the reported general yield for each of the diseases suspected in these patients probably because stronger phenotypes are usually associated with higher diagnostic yield of the genetic test. All but one of the genotype-positive cases of the $\mathrm{Ph}(+) \mathrm{SCA}$ group, carried pathogenic variants consistent with the suspected heart disease, underscoring that phenotyping remains central to the diagnosis of the cause of SCA. Clarifying the clinical role of the potentially disease-causing variants in genes unrelated to the phenotypes, such as the CAV3-variant in a patient with DCM, requires further research and highlights the utility of broader genetic panels for research purposes.

The possible genetic nature of SCA in the absence of measurable heart disease has been first recognized in 2000 , when the p.Ser1710Leu mutant sodium channel has been shown to be the likely molecular substrate for $\mathrm{Ph}(-) \mathrm{SCA} .{ }^{9}$ Subsequently, detailed experimental and familial studies have established the causality for the Dutch founder haplotype in $D P P 6,{ }^{10}$ mutations in CALM1, IRX $3,{ }^{12}$ and $R Y R 2 .{ }^{13}$ Moreover, recent studies on $\mathrm{Ph}(-)$ SCA cohorts found mutations in cardiac ion channel genes (RYR2, KCNH2, KCNQ1,KCNE1, SCN5A, and CACNA1C) and cardiomyopathy-associated genes (LMNA, TTN, DSP, PLN, DSC2, MYBPC3, MYH7, TNNT2), with a diagnostic yield of up to $15 \%$, thus further expanding the spectrum of genes potentially associated with $\mathrm{Ph}(-) \mathrm{SCA} .{ }^{3,14}$ We identified a genetic substrate that explains nearly one-sixth of our $\mathrm{Ph}(-) \mathrm{SCA}$ cases. More than half of these mutations were located in principal cardiac ion 
channel genes. This yield is consistent with previous reports, ${ }^{3,14,15}$ and highlights that concealed cardiac channelopathies may manifest with malignant arrhythmias even in the absence of a detectable cardiac phenotype.

Four out of 6 mutations detected in our $\mathrm{Ph}(-) \mathrm{SCA}$ cohort were located in $R Y R 2$, making CPVT the most prevalent diagnosis in this group (11\%). Two CPVT patients (\#3 and \#9) had a history of syncopal episodes preceding SCA with no direct link to exercise. Another patient (\#5) had frequent premature ventricular contractions and a non-sustained VT at maximum exercise load, which did not raise a suspicion of CPVT. The fourth patient (\#6) had a negative exercise test but experienced a VT at follow up terminated with an ICD shock. These data, in line with recent reports, ${ }^{15}$ indicate the need for a low threshold to suspect CPVT and to perform a confirmatory genetic test in $\mathrm{Ph}(-) \mathrm{SCA}$ survivors with equivocal stress test findings.

The remaining putative pathogenic váriants affected genes encoding the ion channel TRPM4 (TRPM4), ion channel interacting proteins (RANGRF, ABCC9) or myocardial structural proteins $(D S P, T T N)$. Mutations in the TRPM4 channel gene have been implicated in progressive familial heart block, atrioventricular block, right bundle-branch block, and Brugada syndrome (BrS). ${ }^{16}$ Although the TRPM4 channel is known to be involved in cellular calcium regulation, its exact role in the cardiac physiology and pathophysiology remains unclear. Loss-of-function RANGRF mutations have been reported to cause BrS through impairing the trafficking of Nav1.5 channel. 17 Likewise, gain-of-function mutations in $A B C C 9$, a critical gene for the activation and regulation of the $K_{\text {ATP }}$ channels, were shown to result in increased $\mathrm{I}_{\mathrm{KATP}}$ current and manifest with $\mathrm{BrS}^{18}$ Mutations in DSP (desmoplakin) have been implicated in $\mathrm{ARVC}^{19}$ and $\mathrm{DCM} .^{20}$ Desmoplakin disease has been shown to cause connexin mislocalization and result in significant alterations in conduction-repolarization abnormalities prior to morphological changes. ${ }^{21}$ Radical mutations in TTN have been linked mainly to $\mathrm{DCM},{ }^{23}$ with overlaps with other cardiomyopathies 
and are known to confer high arrhythmic potential. Despite the presumed pathogenic role of these variants, their potential causality in $\mathrm{Ph}(-) \mathrm{SCA}$ is subject to further evaluation in functional and follow-up studies. These patients would therefore need close surveillance for detection of any related phenotype at follow-up.

Our findings are particularly interesting in the context of the current HRS/ EHRA guidelines, which discourage the use of genetic testing in $\mathrm{Ph}(-) \mathrm{SCA}^{2,}{ }^{7}$ On the contrary, consideration of genetic testing in SADS is recommended (IIa). ${ }^{2,7}$ The main difference between these two groups is that survivors reach the hospital alive and SADS victims to the morgue. Previous studies have found a genetic cause in $25 \%$ of SADS cases. ${ }^{24}{ }^{25}$ In such cases, cascade screening reveals a cardiac disease in nearly half of relatives, ${ }^{6}$ who can benefit from regular surveillance, lifestyle recommendations, and preventive therapy. Our results indicate that the yield of the genetic test in survivors of $\mathrm{Ph}(-) \mathrm{SCA}(17 \%)$ is similar to those in SADS victims. Additionally, our analysis uncovered cardiomyopathy gene mutations in $\mathrm{Ph}(-) \mathrm{SCA}$ patients, which is in accordance with studies on SADS and requires further studies. ${ }^{25}$ Predictive genetic testing in $\mathrm{Ph}(-)$ SCA patients' family members can therefore be as useful as in relatives of SADS victims. ${ }^{2,7}$

Similar to previous studies, the use of large gene panels in our study led to high yield of VUS, particularly in the $\mathrm{Ph}(-)$ SCA group (47\%). The clinical implication of these variants remain elusive and require further studies. Mutations in minor cardiomyopathy or channelopathy genes, defined as implicated in $<5 \%$ of disease cases, were identified in $8(13 \%)$ SCA patients. These included mutations in $R A N G R F, A B C C 9, F K T N, K C N E 2$ in patients with $\mathrm{Ph}(-) \mathrm{SCA}$ and $L A M P 2$, BAG3, HCN4, CAV3, FLNC, and JPH2 in patients with $\mathrm{Ph}(+) \mathrm{SCA}$.

Our results suggest that genetic testing is useful in all SCA survivors with and without evidence of cardiac disease. Nevertheless, the test should be performed only by experienced and 
accredited laboratories to avoid potential erroneous assignment of pathogenicity. ${ }^{3}$ Longitudinal prognostic studies of a large cohort of genetically tested SCA survivors and their family members are necessary to determine the potential role of mutation status for risk stratification. The progress in the understanding of the genotype-phenotype associations and the evolving variant classification schemes will optimistically solve the puzzle of uncertain variants and provide more reliable criteria for assessment of pathogenicity

Our study has several limitations. The number of enrolled patients in the present study was relatively small, an inherent problem in studies conducted on rare diseases. Our cohort included only SCA survivors referred for genetic testing. Although the classification of the variants stringently followed the ACMG guidelines, we cannot definitely conclude on their pathogenicity in the absence of segregation or functional studies, although this may be hampered by an incomplete penetrance of the variants. We did not investigate whether a carrier status of a putative pathogenic variant confers a risk for recurrent cardiac events, or whether mutationcarrier $\mathrm{Ph}(-)$ SCA patients develop a phenotype at follow-up. Finally, we lack clinical and genetic data of the families, which could help better interpret the impact of many variants.

In conclusion, comprehensive cardiac panel genetic testing identified mutations linked to channelopathies and/ or cardiomyopathies in nearly half of SCA survivors without previous diagnosis of cardiac disease. Genetic testing revealed a putative pathogenic variant compatible with the phenotype in $67 \%$ of $\mathrm{Ph}(+)$ SCA cases. In the $\mathrm{Ph}(-)$ SCA group, genetic test revealed the cause of arrest in $17 \%$ of cases, similar to the yield reported in SADS. Majority of mutations identified in $\mathrm{Ph}(-) \mathrm{SCA}$ patients were associated with channelopathies, most commonly CPVT, whereas in the $\mathrm{Ph}(+) \mathrm{SCA}$ group, the mutations were mostly located in cardiomyopathyassociated genes. Since genetic testing facilitated the understanding of one-sixth of $\mathrm{Ph}(-) \mathrm{SCA}$ cases, the test is recommended in all SCA survivors, with or without a cardiac phenotype, as it 
allows to guide treatment decisions. This study also highlights the need for long-term follow-up studies to examine the prognostic value of genetic findings in SCA survivors.

\section{Acknowledgements}

BA received a Swiss Government Excellence Scholarship for Doctoral Studies (ref № 2015.0138). This study was funded by the Swiss Heart Foundation through a research grant to AMD.

1.Hayashi M, Shimizu W and Albert CM. The spectrum of epidemiology underlying sudden cardiac death. Circ Res. 2015;116:1887-906.

2.Ackerman MJ, Priori SG, Willems S, Berul C, Brugada R, Calkins H, Camm AJ, Ellinor PT, Gollob M, Hamilton R, Hershberger RE, Judge DP, Le Marec H, McKenna WJ, Schulze-Bahr E, Semsarian C, Towbin JA, Watkins H, Wilde A, Wolpert C and Zipes DP. HRS/EHRA expert consensus statement on the state of genetic testing for the channelopathies and cardiomyopathies this document was developed as a partnership between the Heart Rhythm Society (HRS) and the European Heart Rhythm Association (EHRA). Heart Rhythm. 2011;8:1308-39.

3.Mellor G, Laksman ZWM, Tadros R, Roberts JD, Gerull B, Simpson CS, Klein GJ, Champagne J, Talajic M, Gardner M, Steinberg C, Arbour L, Birnie DH, Angaran P, Leather R, Sanatani S, Chauhan VS, Seifer C, Healey JS and Krahn AD. Genetic Testing in the Evaluation of Unexplained Cardiac Arrest: From the CASPER (Cardiac Arrest Survivors With Preserved Ejection Fraction Registry). Circ Cardiovasc Genet. 2017;10.

4.Herman AR, Cheung C, Gerull B, Simpson CS, Birnie DH, Klein GJ, Champagne J, Healey JS, Gibbs K, Talajic M, Gardner M, Bennett MT, Steinberg C, Janzen M, Gollob MH, Angaran P, Yee R, Leather R, Chakrabarti S, Sanatani S, Chauhan VS and Krahn AD. Outcome of Apparently Unexplained Cardiac Arrest: Results From Investigation and Follow-Up of the 
Prospective Cardiac Arrest Survivors With Preserved Ejection Fraction Registry. Circ Arrhythm Electrophysiol. 2016;9:e03619.

5.Jimenez-Jaimez J, Peinado R, Grima EZ, Segura F, Morina P, Sanchez Munoz JJ, Mazuelos F, Cozar R, Gimeno JR, Heras RP, Monserrat L, Domingo D, Ortiz-Genga M, Fernandez Pastor J, Alvarez M and Tercedor L. Diagnostic Approach to Unexplained Cardiac Arrest (from the FIVIGen Study). Am J Cardiol. 2015;116:894-9.

6.Kumar S, Peters S, Thompson T, Morgan N, Maccicoca I, Trainer A, Zentner D, Kalman JM, Winship I and Vohra JK. Familial cardiological and targeted genetic evaluation: low yield in sudden unexplained death and high yield in unexplained cardiac arrest syndromes. Heart Rhythm. 2013;10:1653-60.

7.Priori SG, Wilde AA, Horie M, Cho Y, Behr ER, Berul C, Blom N, Brugada J, Chiang CE, Huikuri H, Kannankeril P, Krahn A, Leenhardt A, Moss A, Schwartz PJ, Shimizu W, Tomaselli $\mathrm{G}$ and Tracy C. HRS/EHRA/APHRS expert consensus statement on the diagnosis and management of patients with inherited primary arrhythmia syndromes: document endorsed by HRS, EHRA, and APHRS in May 2013 and by ACCF, AHA, PACES, and AEPC in June 2013. Heart Rhythm. 2013;10:1932-63.

8.Richards S, Aziz N, Bale S, Bick D, Das S, Gastier-Foster J, Grody WW, Hegde M, Lyon E, Spector E, Voelkerding K, Rehm HL and Committee ALQA. Standards and guidelines for the interpretation of sequence variants: a joint consensus recommendation of the American College of Medical Genetics and Genomics and the Association for Molecular Pathology. Genet Med. 2015;17:405-24.

9.Akai J, Makita N, Sakurada H, Shirai N, Ueda K, Kitabatake A, Nakazawa K, Kimura A and Hiraoka M. A novel SCN5A mutation associated with idiopathic ventricular fibrillation without typical ECG findings of Brugada syndrome. FEBS Lett. 2000;479:29-34. 
10.Alders M, Koopmann TT, Christiaans I, Postema PG, Beekman L, Tanck MW, Zeppenfeld K, Loh P, Koch KT, Demolombe S, Mannens MM, Bezzina CR and Wilde AA. Haplotype-sharing analysis implicates chromosome 7q36 harboring DPP6 in familial idiopathic ventricular fibrillation. Am J Hum Genet. 2009;84:468-76.

11.Marsman RF, Barc J, Beekman L, Alders M, Dooijes D, van den Wijngaard A, Ratbi I, Sefiani A, Bhuiyan ZA, Wilde AA and Bezzina CR. A mutation in CALM1 encoding calmodulin in familial idiopathic ventricular fibrillation in childhood and adolescence. $\mathrm{J}$ Am Coll Cardiol. 2014;63:259-66.

12.Koizumi A, Sasano T, Kimura W, Miyamoto Y, Aiba T, Ishikawa T, Nogami A, Fukamizu S, Sakurada H, Takahashi Y, Nakamura H, Ishikura T, Koseki H, Arimura T, Kimura A, Hirao K, Isobe M, Shimizu W, Miura N and Furukawa T. Genetic defects in a His-Purkinje system transcription factor, IRX3, cause lethal cardiac/arrhythmias. Eur Heart J. 2016;37:1469-75.

13.Fujii Y, Itoh H, Ohno S, Murayama T, Kurebayashi N, Aoki H, Blancard M, Nakagawa Y, Yamamoto S, Matsui Y, Ichikawa M, Sonoda K, Ozawa T, Ohkubo K, Watanabe I, Guicheney P and Horie M. A type 2 ryanodine receptor variant associated with reduced $\mathrm{Ca}(2+)$ release and short-coupled torsades de pointes ventricular arrhythmia. Heart Rhythm. 2017;14:98-107.

14.Visser M, van der Heijden JF, van der Smagt JJ, Doevendans PA, Wilde AA, Loh P and Hassink RJ. Long-Term Outcome of Patients Initially Diagnosed With Idiopathic Ventricular Fibrillation: A Descriptive Study. Circ Arrhythm Electrophysiol. 2016;9:e004258.

15.Leinonen JT, Crotti L, Djupsjobacka A, Castelletti S, Junna N, Ghidoni A, Tuiskula AM, Spazzolini C, Dagradi F, Viitasalo M, Kontula K, Kotta MC, Widen E, Swan H and Schwartz PJ. The genetics underlying idiopathic ventricular fibrillation: A special role for catecholaminergic polymorphic ventricular tachycardia? Int J Cardiol. 2018;250:139-145.

16.Liu H, Chatel S, Simard C, Syam N, Salle L, Probst V, Morel J, Millat G, Lopez M, Abriel H, 
Schott JJ, Guinamard R and Bouvagnet P. Molecular genetics and functional anomalies in a series of 248 Brugada cases with 11 mutations in the TRPM4 channel. PLoS One. 2013;8:e54131.

17.Kattygnarath D, Maugenre S, Neyroud N, Balse E, Ichai C, Denjoy I, Dilanian G, Martins RP, Fressart V, Berthet M, Schott JJ, Leenhardt A, Probst V, Le Marec H, Hainque B, Coulombe A, Hatem SN and Guicheney P. MOG1: a new susceptibility gene for Brugada syndrome. Circ Cardiovasc Genet. 2011;4:261-8.

18.Hu D, Barajas-Martinez H, Terzic A, Park S, Pfeiffer R, Burashnikov E, Wu Y, Borggrefe M, Veltmann C, Schimpf R, Cai JJ, Nam GB, Deshmukh P, Scheinman M, Preminger M, Steinberg J, Lopez-Izquierdo A, Ponce-Balbuena D, Wolpert C, Haissaguerre M, Sanchez-Chapula JA and Antzelevitch C. ABCC9 is a novel Brugada and early repolarization syndrome susceptibility gene. Int J Cardiol. 2014;171:431-42.

19.Rampazzo A, Nava A, Malacrida S, Beffagna G, Bauce B, Rossi V, Zimbello R, Simionati B, Basso C, Thiene G, Towbin JA and Danieli GA. Mutation in human desmoplakin domain binding to plakoglobin causes $>$ a dominant form of arrhythmogenic right ventricular cardiomyopathy. Am J Hum Genet. 2002;71:1200-6.

20.Norgett EE, Hatsell SJ, Carvajal-Huerta L, Cabezas JC, Common J, Purkis PE, Whittock N, Leigh IM, Stevens HP and Kelsell DP. Recessive mutation in desmoplakin disrupts desmoplakinintermediate filament interactions and causes dilated cardiomyopathy, woolly hair and keratoderma. Hum Mol Genet. 2000;9:2761-6.

21.Gomes J, Finlay M, Ahmed AK, Ciaccio EJ, Asimaki A, Saffitz JE, Quarta G, Nobles M, Syrris P, Chaubey S, McKenna WJ, Tinker A and Lambiase PD. Electrophysiological abnormalities precede overt structural changes in arrhythmogenic right ventricular cardiomyopathy due to mutations in desmoplakin-A combined murine and human study. Eur 
Heart J. 2012;33:1942-53.

22.Bhonsale A, Groeneweg JA, James CA, Dooijes D, Tichnell C, Jongbloed JD, Murray B, te Riele AS, van den Berg MP, Bikker H, Atsma DE, de Groot NM, Houweling AC, van der Heijden JF, Russell SD, Doevendans PA, van Veen TA, Tandri H, Wilde AA, Judge DP, van Tintelen JP, Calkins H and Hauer RN. Impact of genotype on clinical course in arrhythmogenic right ventricular dysplasia/cardiomyopathy-associated mutation carriers. Eur Heart J. 2015;36:847-55.

23.Herman DS, Lam L, Taylor MR, Wang L, Teekakirikul P, Christodoulou D, Conner L, DePalma SR, McDonough B, Sparks E, Teodorescu DL, Cirino AL, Banner NR, Pennell DJ, Graw S, Merlo M, Di Lenarda A, Sinagra G, Bos JM, Ackerman MJ, Mitchell RN, Murry CE, Lakdawala NK, Ho CY, Barton PJ, Cook SA, Mestroni L, Seidman JG and Seidman CE. Truncations of titin causing dilated cardiomyopathy. N Engl J Med. 2012;366:619-28.

24.Tester DJ, Medeiros-Domingo A, Will ML, Haglund CM and Ackerman MJ. Cardiac channel molecular autopsy: insights from 173 consecutive cases of autopsy-negative sudden unexplained death referred for postmortem genetic testing. Mayo Clin Proc. 2012;87:524-39.

25.Bagnall RD, Weintraub RG, Ingles J, Duflou J, Yeates L, Lam L, Davis AM, Thompson T, Connell V, Wallace J, Naylor C, Crawford J, Love DR, Hallam L, White J, Lawrence C, Lynch M, Morgan N, James P, du Sart D, Puranik R, Langlois N, Vohra J, Winship I, Atherton J, McGaughran J, Skinner JR and Semsarian C. A Prospective Study of Sudden Cardiac Death among Children and Young Adults. N Engl J Med. 2016;374:2441-52.

26. Chua HC, Servatius H, Asatryan B, Schaller A, Rieubland C, Noti F, Seiler J, Roten L, Baldinger SH, Tanner H, Fuhrer J, Haeberlin A, Lam A, Pless SA and Medeiros-Domingo A. Unexplained cardiac arrest: a tale of conflicting interpretations of KCNQ1 genetic test results. Clin Res Cardiol. 2018;107:670-678. 


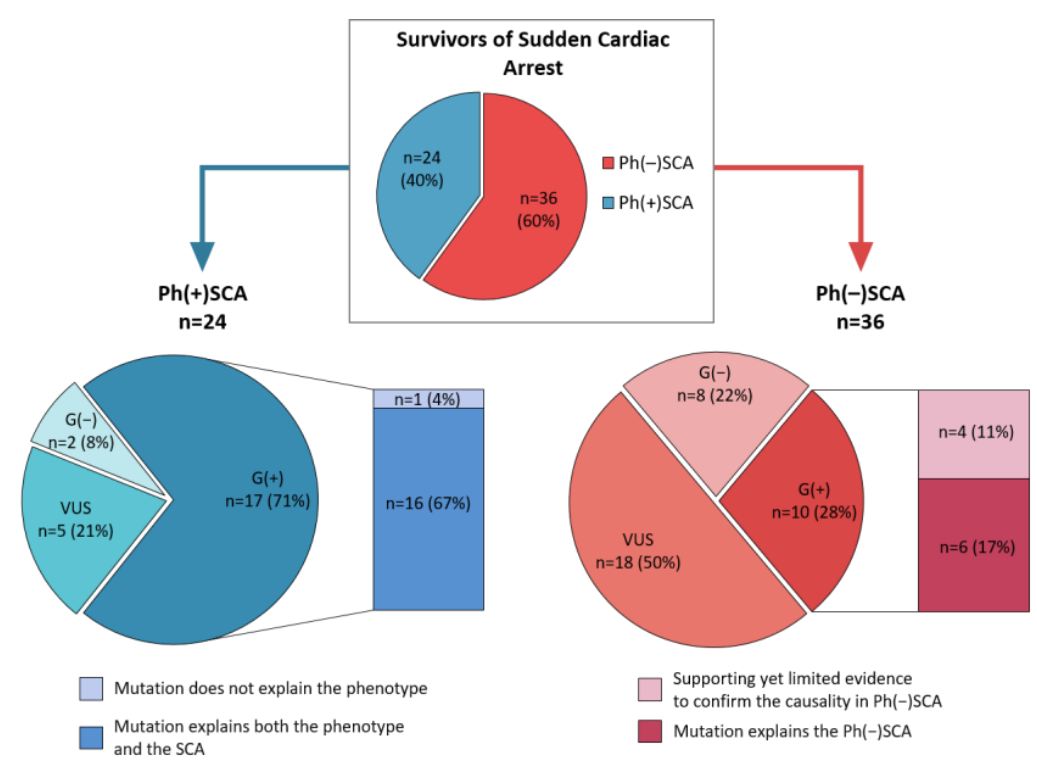

Figure 1. The results and the interpretation of genetic test findings in survivors of sudden cardiac arrest with and without evident clinical cardiac phenotype. G, genotype; Ph, phenotype; SCA, sudden cardiac arrest; VUS, variant of uncertain significance.

Table 1. Demographic characteristics and genetic test results in sudden cardiac arrest survivors referred for cardiovascular genetic testing, grouped based on the displayed cardiac phenotype.

\begin{tabular}{lcccc}
\hline \multicolumn{1}{c}{ Characteristic } & $\begin{array}{r}\text { All patients } \\
\text { with SCA }\end{array}$ & $\begin{array}{c}\text { Patients with } \\
\mathrm{Ph}(+) \mathrm{SCA}\end{array}$ & $\begin{array}{c}\text { Patients with } \\
\mathrm{Ph}(-) \mathrm{SCA}\end{array}$ & $\begin{array}{c}P \text {-value * } \\
\end{array}$ \\
$\begin{array}{lccc}\text { No. of probands } \\
\text { Age at SCA, y, median (IQR) }\end{array}$ & $34(20-43)$ & $36(20-46)$ & $34(20-42)$ & 0.490 \\
Male gender & $49(82 \%)$ & $21(87 \%)$ & $28(78 \%)$ & 0.274 \\
Patients aged $\leq 35 \mathrm{yrs}$ & $32(53 \%)$ & $12(50 \%)$ & $20(56 \%)$ & 0.673 \\
$\quad$ Male & $27(84 \%)$ & $10(83 \%)$ & $17(85 \%)$ & 0.674 \\
$\quad$ Female & $5(16 \%)$ & $2(17 \%)$ & $3(15 \%)$ & \\
Genetic test results & & & & \\
$\quad$ Positive & $27(45 \%)$ & $17(71 \%)$ & $10(28 \%)$ & $\mathbf{0 . 0 0 1}$ \\
\hline
\end{tabular}




\begin{tabular}{ccccc}
\hline Male & $23(85 \%)$ & $15(88 \%)$ & $8(80 \%)$ & 0.561 \\
Female & $4(15 \%)$ & $2(12 \%)$ & $2(20 \%)$ & \\
VUS & $23(38 \%)$ & $5(21 \%)$ & $18(50 \%)$ & \\
Male & $18(78 \%)$ & $4(80 \%)$ & $14(78 \%)$ & 0.709 \\
Female & $5(22 \%)$ & $1(20 \%)$ & $4(22 \%)$ & \\
Negative & $10(17 \%)$ & $2(8 \%)$ & $8(22 \%)$ & \\
Male & $8(80 \%)$ & $2(100 \%)$ & $6(75 \%)$ & 0.622 \\
Female & $2(20 \%)$ & $0(0 \%)$ & $2(25 \%)$ & \\
\hline
\end{tabular}

Abbreviations: $\mathrm{Ph}$, phenotype; SCA, sudden cardiac arrest; SD, standard deviation; VUS, variant of uncertain significance.

* P values are for binomial test, t-test, Fisher's exact test, or Chi-Square test, as appropriate. ChiSquare test was used to test for gender differences between phenotype groups in the whole population, as well as in subgroups according to age and genetic test results. 
Table 2. Summary of clinical and genetic characteristics of sudden cardiac arrest survivors.

\begin{tabular}{|c|c|c|c|c|c|c|c|c|c|c|c|c|c|c|c|}
\hline $\begin{array}{l}\text { Case } \\
\#\end{array}$ & Gender & $\begin{array}{l}\text { Age at } \\
\text { SCA, } \\
y\end{array}$ & $\begin{array}{l}\text { Phenotype } \\
\text { category }\end{array}$ & Cardiac Phenotype & $\begin{array}{l}\text { Circumstances } \\
\text { of the event }\end{array}$ & Gene & $\begin{array}{l}\text { Reference } \\
\text { sequence no. }\end{array}$ & Nucleotide change & Protein change & $\begin{array}{l}\text { Variant } \\
\text { type }\end{array}$ & $\begin{array}{l}\text { Homo-/ } \\
\text { Heterozygous }\end{array}$ & dbSNP ID & $\begin{array}{l}\text { AF in } \\
\text { gnomAD } \\
\text { (European } \\
\text { non- } \\
\text { Finnish) }\end{array}$ & $\begin{array}{l}\text { MAF in } \\
\text { ExAC }\end{array}$ & $\begin{array}{l}\text { ACMG } \\
\text { variant } \\
\text { class }\end{array}$ \\
\hline \multirow[t]{2}{*}{1} & M & 56 & $\mathrm{Ph}(-) \mathrm{SCA}$ & - & exercise unrelated & RANGRF & NM_16492.4 & $c .198 \mathrm{C}>\mathrm{A}$ & p. Tyr6 6* & nonsense & heterozygous & rs1223777741 & 0.00001758 & $\mathrm{~N} / \mathrm{A}$ & LP \\
\hline & & & & & & DES & NM_001927.3 & $c .742 \mathrm{C}>\mathrm{T}$ & & & heterozygous & rs772117708 & 0.000008920 & 0.000008 & vUs \\
\hline \multirow[t]{2}{*}{2} & M & 17 & $\mathrm{Ph}(-) \mathrm{SCA}$ & - & unknown & SCN5A & NM_001099404.1 & c. $2441 \mathrm{G}>\mathrm{A}$ & p.Arg814Gln & missense & heterozygous & rs199473584 & 0.00003158 & 0.000018 & LP \\
\hline & & & & & & SNTA1 & NM_003098.2 & $c .566 \mathrm{C}>\mathrm{T}$ & p.Ser189Leu & missense & heterozygous & rs 144860423 & 0.0003642 & 0.0002 & vUs \\
\hline 3 & $\mathrm{~F}$ & 5 & $\mathrm{Ph}(-) \mathrm{SCA}$ & - & exercise unrelated & RYR2 & NM_001035.2 & c. $6737 \mathrm{C}>\mathrm{T}$ & p.Ser2246Leu & missense & heterozygous & rs121918597 & $\mathrm{N} / \mathrm{A}$ & N/A & $\mathrm{P}$ \\
\hline 4 & M & 17 & $\mathrm{Ph}(-) \mathrm{SCA}$ & - & exercise-related & $A B C C 9$ & NM_020297.3 & c. $1320+1 G>A$ & p.(?) & splice region & heterozygous & rs139620148 & 0.00003899 & 0.000058 & LP \\
\hline 5 & $\mathrm{~F}$ & 17 & $\mathrm{Ph}(-) \mathrm{SCA}$ & - & exercise unrelated & RYR2 & NM_001035.2 & $c .365 \mathrm{G}>\mathrm{A}$ & p.Arg122His & missense & homozygous & rs727503396 & $\mathrm{N} / \mathrm{A}$ & $N / A$ & LP \\
\hline 6 & M & 47 & $\mathrm{Ph}(-) \mathrm{SCA}$ & - & unknown & RYR2 & NM_001035.2 & c. $1250 \mathrm{G}>\mathrm{A}$ & p.Arg417Gln & missense & heterozygous & rs751428303 & 0.00001559 & 0.000025 & LP \\
\hline \multirow[t]{2}{*}{7} & M & 28 & $\mathrm{Ph}(-) \mathrm{SCA}$ & - & exercise unrelated & $D S P$ & NM_004415.2 & c. $4775 \mathrm{~A}>\mathrm{G}$ & p.Lys1592Arg & missense & heterozygous & rs200421954 & 0.0003817 & 0.000185 & LP \\
\hline & & & & & & TTN & NM_001256850 & c. $29732-2 A>T$ & p.? & splice region & heterozygous & novel variant & N/A & N/A & $\mathrm{P}$ \\
\hline \multirow[t]{2}{*}{8} & $\mathrm{~F}$ & 34 & $\mathrm{Ph}(-) \mathrm{SCA}$ & - & unknown & TRPM4 & NM_017636 & c. $2387 \mathrm{~T}>\mathrm{C}$ & p.Leu796Pro & missense & heterozygous & rs1191927360 & $\mathrm{N} / \mathrm{A}$ & N/A & vUs \\
\hline & & & & & & FKTN & NM_001079802 & c.1380dupA & p. Tyr461llefs*? & frameshift & heterozygous & rs775366895 & 0.00004399 & N/A & LP* \\
\hline \multirow[t]{2}{*}{9} & M & 38 & $\mathrm{Ph}(-) \mathrm{SCA}$ & - & exercise-related & RYR2 & NM_001035.2 & c. $1346 \mathrm{~T}>\mathrm{G}$ & p.lle449Arg & missense & heterozygous & rs373331669 & 0.00001777 & 0.000008 & LP \\
\hline & & & & & & $D S P$ & NM_004415.2 & c. $2462 A>G$ & p.Lys821Arg & missense & heterozygous & novel variant & N/A & N/A & vus \\
\hline \multirow[t]{2}{*}{$10^{* *}$} & M & 2 & $\mathrm{Ph}(-) \mathrm{SCA}$ & - & unknown & KCNE2 & NM_172201.1 & $c .170 T>C$ & p.lle57Thr & missense & heterozygous & rs74315448 & 0.001045 & 0.0009 & P† \\
\hline & & & & & & CACNB2 & NM_201593.3 & $c .410 \mathrm{G}>\mathrm{A}$ & p.Gly137Asp & missense & heterozygous & rs754596850 & 0.000008799 & 0.000008 & vUs \\
\hline \multirow[t]{3}{*}{11} & M & 28 & $\mathrm{Ph}(-) \mathrm{SCA}$ & - & unknown & SCN5A & NM_001099404.1 & $c .3929 \mathrm{C}>\mathrm{T}$ & p.Pro1310Leu & missense & heterozygous & novel variant & $N / A$ & N/A & vUs \\
\hline & & & & & & RYR2 & NM_001035.2 & $c .7570 G>A$ & p.Val2524lle & missense & heterozygous & rs934248102 & 0.00003893 & $N / A$ & vUs \\
\hline & & & & & & TTN & NM_001267550.1 & c.1545_1549delAGAAA & p.Lys515AsnfsTer2 & frameshift & heterozygous & novel variant & $\mathrm{N} / \mathrm{A}$ & $N / A$ & LP \\
\hline \multirow[t]{2}{*}{$12^{* *}$} & M & 22 & $\mathrm{Ph}(-) \mathrm{SCA}$ & - & exercise unrelated & KCNQ1 & NM_000218.2 & c.190_210delCCTGCGTCCCCGGCCGCGCCC & p.Pro64_Pro70del & deletion & heterozygous & $\begin{array}{l}\text { reported, no } \\
\text { dbSNP ID }\end{array}$ & $\mathrm{N} / \mathrm{A}$ & N/A & vus $\ddagger$ \\
\hline & & & & & & PKP2 & NM_004572.3 & c. $2431 \mathrm{C}>\mathrm{A}$ & p.Arg811Ser & missense & heterozygous & rs139734328 & 0.0009214 & 0.00087 & vUs \\
\hline \multirow[t]{2}{*}{13} & M & 19 & $\mathrm{Ph}(-) \mathrm{SCA}$ & - & exercise unrelated & AKAPg & NM_005751 & c. $10664 \mathrm{~A}>\mathrm{T}$ & p.Asp3555Val & missense & heterozygous & rs 139046510 & 0.001444 & 0.0009 & vUs \\
\hline & & & & & & TNXB & NM_019105.6 & c. $5956 \mathrm{~A}>\mathrm{G}$ & p.lle1986Val & missense & heterozygous & rs201365475 & 0.000008873 & $N / A$ & vUs \\
\hline 14 & $\mathrm{~F}$ & 41 & $\mathrm{Ph}(-) \mathrm{SCA}$ & - & exercise-rela & TNNI3 & NM_0,00363 & $c .349 A>G$ & p.Lys117Glu & missense & heterozygous & novel variant & $\mathrm{N} / \mathrm{A}$ & N/A & vus \\
\hline \multirow[t]{2}{*}{15} & M & 28 & $\mathrm{Ph}(-) \mathrm{SCA}$ & - & unknown & DS & NM_004415.2 & c. $2723 \mathrm{G}>\mathrm{A}$ & p.Arg908His & missense & heterozygous & rs142494121 & 0.0009762 & 0.0011 & vUs \\
\hline & & & & & & & 002471.3 & c. $1138 \mathrm{G}>\mathrm{A}$ & p.Glu380Lys & missense & heterozygous & rs768924353 & $N / A$ & 0.000008 & VUS \\
\hline \multirow[t]{2}{*}{16} & M & 24 & $\mathrm{Ph}(-) \mathrm{SCA}$ & - & & CTNNA3 & NM_001127384 & c. $2573 \mathrm{~T}>\mathrm{C}$ & p.Leu858Ser & missense & heterozygous & rs41313840 & 0.0003953 & 0.0003 & vUs \\
\hline & & & & & & KCNE1 & NM_001270402.1 & c. $253 \mathrm{G}>\mathrm{A}$ & p.Asp85Asn & missense & heterozygous & rs 1805128 & 0.01223 & 0.0092 & vUs \\
\hline 17 & M & 35 & $\mathrm{Ph}(-) \mathrm{SCA}$ & - & xercise-related & $\mathrm{KCNH} 2$ & NM_000238 & c. $1653 C>G$ & p.Phe551Leu & missense & heterozygous & novel variant & $\mathrm{N} / \mathrm{A}$ & N/A & VUS \\
\hline 18 & M & 56 & $\mathrm{Ph}(-) \mathrm{SCA}$ & - & xercise-related & FLNC & NM_001458.4 & $c .1616 \mathrm{C}>\mathrm{T}$ & p.Pro539Leu & missense & heterozygous & rs375570393 & 0.000 & 0.000017 & vUs \\
\hline \multirow[t]{2}{*}{19} & M & 41 & $\mathrm{Ph}(-) \mathrm{SCA}$ & - & kno & ANK2 & NM_001148.4 & c.4799T>C & p.lle1600Thr & missense & heterozygous & rs764150279 & 0.00002342 & 0.000033 & vUs \\
\hline & & & & & & $S C N 2 B$ & NM_004588.4 & $c .356 \mathrm{C}>\mathrm{T}$ & p.Pro119Leu & missense & heterozygous & rs767589740 & $\mathrm{N} / \mathrm{A}$ & 0.000200 & vus \\
\hline 20 & M & 38 & $\mathrm{Ph}(-) \mathrm{SCA}$ & & unknown & KCNJ2 & NM_000891.2 & $c .973 \mathrm{C}>\mathrm{T}$ & p.Arg325Cys & missense & heterozygous & rs202067116 & 0.00006197 & 0.000041 & vUs \\
\hline \multirow[t]{2}{*}{21} & M & 31 & $\mathrm{Ph}(-) \mathrm{SCA}$ & & unknown & KCNJ5 & NM_000890 & c. $155 \mathrm{G}>\mathrm{A}$ & P.Arg52His & missense & heterozygous & rs 144062083 & 0.00004396 & 0.000025 & vUs \\
\hline & & & & & & FBN1 & NM_000138 & c. $1307 A>G$ & p.Tyr436Cys & missense & heterozygous & novel variant & $\mathrm{N} / \mathrm{A}$ & N/A & vUs \\
\hline \multirow[t]{2}{*}{22} & M & 34 & & & exercise unrelated & $S C N 10 A$ & NM_006514.3 & c. $3675 \mathrm{~T}>\mathrm{G}$ & p.lle1225Met & missense & heterozygous & rs371834340 & 0.00008519 & 0.000017 & vUs \\
\hline & & & & & & DSG2 & NM_001943.3 & c. $1642 \mathrm{C}>\mathrm{T}$ & p.Arg548Cys & missense & heterozygous & rs550400909 & 0.00003125 & 0.000009 & VUS \\
\hline
\end{tabular}




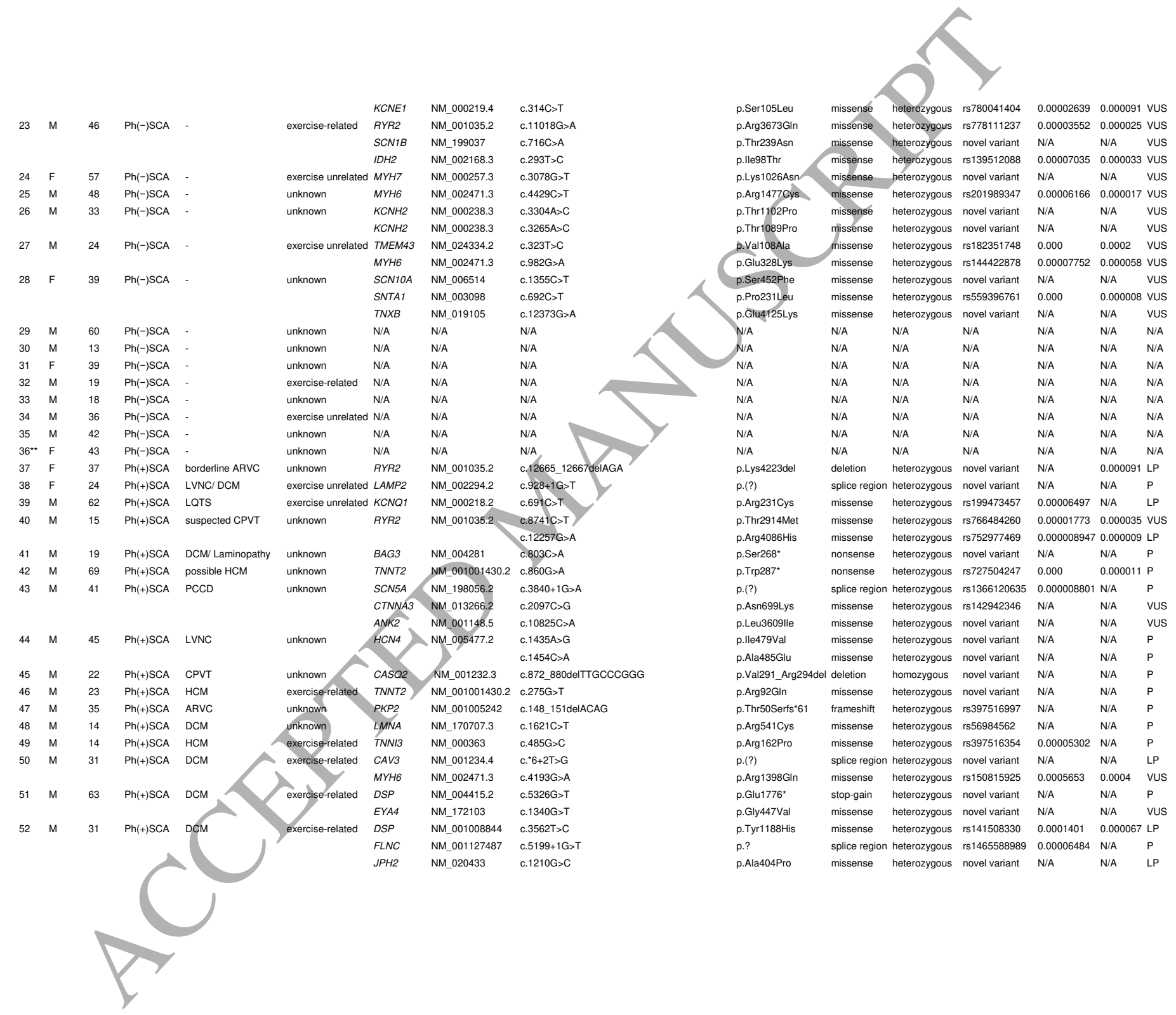




\begin{tabular}{|c|c|c|c|c|c|c|c|c|c|c|c|c|c|c|c|}
\hline & & & & & & $T N X B$ & NM_019105.6 & c. $10990 \mathrm{G}>\mathrm{A}$ & p.Val3664Met & missensé & jous & novel variant & N/A & N/A & LP \\
\hline 53 & M & 43 & $\mathrm{Ph}(+) \mathrm{SCA}$ & DCM & unknown & TTN & NM_001256850 & c.44440dupA & p. Thr14814Ansfs ${ }^{4} 7$ & frameshift & heterozygous & novel variant & N/A & N/A & LP \\
\hline \multirow[t]{2}{*}{54} & M & 9 & $\mathrm{Ph}(+) \mathrm{SCA}$ & possible ARVC & unknown & DSG2 & NM_001943.2 & $c .877 A>G$ & p.lle293Val & missense & heterozygous & rs2230234 & 0.08733 & 0.0687 & vus \\
\hline & & & & & & $D S P$ & NM_004415.2 & c. $6208 \mathrm{G}>\mathrm{A}$ & p.Asp2070Asn & missense & heterozygous & rs41302885 & 0.005636 & 0.0039 & vus \\
\hline \multirow[t]{3}{*}{55} & M & 42 & $\mathrm{Ph}(+) \mathrm{SCA}$ & MVP & exercise unrelated & $T N X B$ & NM_019105.6 & c. $8734 \mathrm{G}>\mathrm{A}$ & p.Gly2912Ser & missense & heterozygous & novel variant & N/A & 0.0007 & vus \\
\hline & & & & & & MYLK & NM_053025.3 & c. $4169 \mathrm{~A}>\mathrm{C}$ & p.Asn1390Thr & missense & heterozygous & novel variant & N/A & N/A & vus \\
\hline & & & & & & HCN4 4 & NM_005477.2 & c. $2800 \mathrm{C}>\mathrm{T}$ & p.Arg934Cys & missense & heterozygous & rs199638465 & 0.00008081 & 0.0006 & vUs \\
\hline \multirow[t]{3}{*}{56} & M & 40 & $\mathrm{Ph}(+) \mathrm{SCA}$ & HCM & unknown & TMPO & NM_003276 & c. $689 \mathrm{G}>\mathrm{A}$ & p.Arg23OHis & missense & heterozygous & rs758666714 & 0.00002324 & 0.000025 & vus \\
\hline & & & & & & AKAPG & NM_005751 & c. $9830 \mathrm{~T}>\mathrm{C}$ & & missense & heterozygous & rs 144021475 & 0.0001937 & 0.000008 & vus \\
\hline & & & & & & GJD4 & NM_153368 & c. $259 \mathrm{C}>\mathrm{T}$ & eu87P! & missense & heterozygous & rs76906304 & 0.01812 & 0.013 & vus \\
\hline 57 & $\mathrm{~F}$ & 17 & $\mathrm{Ph}(+) \mathrm{SCA}$ & suspected SQTS & unknown & CACNA2D1 & NM_000722 & c. $2264 \mathrm{G}>\mathrm{C}$ & p.Ser755Thr & missense & heterozygous & rs 151327713 & 0.0006633 & 0.0008 & vus \\
\hline 58 & M & 47 & $\mathrm{Ph}(+) \mathrm{SCA}$ & MVP & exercise unrelated & MYHG & NM_002471 & c. $2383 \mathrm{C}>\mathrm{T}$ & p.Arg795Trp & missense & heterozygous & rs202120238 & 0.0002014 & 0.000074 & vus \\
\hline 59 & M & 50 & $\mathrm{Ph}(+) \mathrm{SCA}$ & possible ARVC & exercise-related & $\mathrm{N} / \mathrm{A}$ & N/A & N/A & & N/A & N/A & N/A & N/A & N/A & $N / A$ \\
\hline 60 & M & 59 & $\mathrm{Ph}(+) \mathrm{SCA}$ & DCM & exercise unrelated & N/A & N/A & N/A & N/A & N/A & N/A & $N / A$ & N/A & N/A & $N / A$ \\
\hline
\end{tabular}

Abbreviations: ACMG, American College of Medical Genetics and Genomics; ARVC, arrhythmogenic right ventricular cardiomyopathy; DCM, dilated cardiomyopathy; HCM, hypertrophic cardiomyopathy; LP, likely pathogenic; LVNC, left ventricular non-compaction; MVP, mitral valve prolapse; P, pathogenic; Ph, phenotype; SCA, sudden cardiac arrest; SD, standard deviation; SQTS, short QT syndrome; VUS, variant of uncertain significance. N/A denotes 'not applicable'.

* FKTN-mediated diseases (DCM or muscular dystrophy-dystroglycanopathy) are transmitted as an autosomal-recessive trait; therefore, the identified heterozygous pathogenic variant is not considered to have a direct link to the SCA.

** Indicates patients who were successfully resuscitated, but died during hospitalization due to neurological complications caused by prolonged cerebral ischemia

$\dagger$ This variant has been initially interpreted as pathogenic; however, the recent evidence suggests contradictory results, and the variant may also be considered as VUS.

\$ This variant has been initially interpreted as pathogenic based on the available literature, but has been later reclassified as a VUS after additional in vitro patch clump experiments and segregation studies revealed no evidence of pathogenicity. ${ }^{26}$

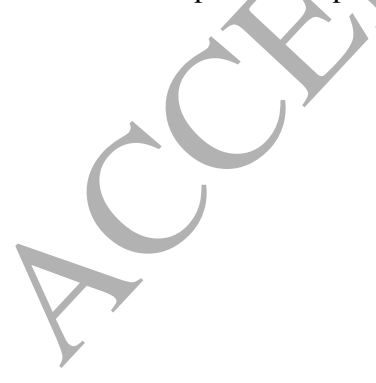

